\title{
Model Output Statistics to improve severe storms prediction over Western Sahel
}

\author{
O.S. Idowu ${ }^{\mathrm{a}, \mathrm{b}, *}$, C.J.deW Rautenbach ${ }^{\mathrm{a}}$ \\ a Department of Geography, Geoinformatics and Meteorology, University of Pretoria, Pretoria, South Africa \\ ${ }^{\mathrm{b}}$ Central Forecast Office, Nigerian Meteorological Agency, Lagos, Nigeria
}

\section{A R T I C L E I N F O}

\section{Article history:}

Accepted 30 October 2008

Available online xxxx

\section{Keywords:}

Severe storms

Numerical weather prediction

Model Output Statistics

MOS equations

\begin{abstract}
A B S T R A C T
The recent increasing trend in the severity of floods, especially across West Africa has been due largely to severe storm outbreaks which are complex and difficult to predict. Most of the weather forecasting centers in Africa now use numerical weather prediction (NWP) model outputs to predict the occurrence and severity of these storms. However, several studies have shown that NWP models and their forecasts are subject to errors and biases because of the complex atmospheric uncertainties and the currently limited knowledge of the mathematical formulation of the atmospheric physics and dynamics. The incorporation of statistical techniques is therefore useful and has indeed become a necessary component of improving NWP model products. Model Output Statistics (MOS), for example, use large multiple regression equations to provide a statistical relationship between the forecast output of NWP models and the observed variables. This study investigates the implementation of the MOS equations generated for Western Sahel (WS), required to correct forecast biases and errors from the $20 \mathrm{~km} \times 20 \mathrm{~km}$ resolution Limited Area Model over Africa (Africa LAM) developed by the United Kingdom Meteorological Office (UK Met Office). Daily observed rainfall from January 2005 to December 2006, of 36 selected meteorological stations regionally distributed across the WS as well as the $\mathrm{T}+24 \mathrm{~h}$ rainfall forecasts from the Africa LAM over the same period were retrieved and analyzed. Results indicated about 76\% improvement to the original Africa LAM rainfall forecasts by the MOS method over the southern region of the WS during July-AugustSeptember-the period when severe storm activities are highly probable. Results also showed a consistently smaller root mean squared error (RMSE) values from the MOS-corrected rainfall forecasts when compared with the RMSEs from the original Africa LAM rainfall forecasts for all the seasons and regions of the WS.
\end{abstract}

(c) 2008 Elsevier B.V. All rights reserved.

\section{Introduction}

Rainfall and most especially severe storms are strongly dependent on the motion, moisture content, and the physical processes of the atmosphere which are not perfectly predictable in a deterministic sense. The atmosphere is regarded as a non-linear dynamic system with many incompletely re-

* Corresponding author. Department of Geography, Geoinformatics and Meteorology, University of Pretoria, Pretoria, South Africa. Tel.: +27 124205164; fax: +27 124203284 .

E-mail addresses: osidowu@up.ac.za (O.S. Idowu), hannes.rautenbach@up.ac.za (C.J. Rautenbach). solved physical parameterizations. In numerical weather prediction (NWP) models, surface conditions are simplified and homogenized and the atmosphere is treated as a medium that consists of square parcels. Land use characteristics are also represented in these models as an array of grid boxes and the associated grid boxes extend through horizontal layers in the vertical atmosphere. Within surface grid boxes, one finds smoothed values of small-scale boundary conditions such as topography, vegetation, soil types, or even small-scale bodies of water; which are spatially variable in reality and very important to local weather conditions. These inaccuracies in NWP models are due to the current limited knowledge of the complex processes in the atmosphere, and probably more 
important, because of the limitations in the ability of modern computers to resolve all model equations over an acceptable time period.

The south-north propagation of the Inter-tropical Discontinuity (ITD) across the Western Sahel (WS) plays an important role in the seasonal variation and distribution of rainfall, and more importantly, in the intensity, duration, and characteristics of severe storms across the region. On the average, the ITD retreats to its most southern position over the WS (close to the equator) in January, and advances to its most northern position (around latitude $20.0^{\circ} \mathrm{N}$ ) in July. During July, the easterly trade wind crosses the geographical equator, and under the influence of the Coriolis force turns westward to form the West African Monsoon (WAM). The WAM which is a moist and onshore maritime air from the Atlantic Ocean prevails over most of the WS in July while the dry and dusty offshore continental winds blowing across the Sahara desert toward the region prevails in January. There are a wide range of extensive convection and cloud developments within the ITD and accordingly five major weather zones (A to E) have been defined over the WS (see Ojo, 1977; Odekunle, 2004; Omotosho, 2008). More than $90 \%$ of the severe storms over WS especially during the peak of the rain (July-August-September) occur within the weather zone C, which is about $200 \mathrm{~km}$ south of the ITD. These storms are strongly dependent on the vertical wind shear associated with the African Easterly Jet (AEJ) located around the $700 \mathrm{hPa}$ level (Le Barbe et al., 2002; Omotosho, 2008).

Apart from the ITD, the severity of rainfall events over the WS is also characterized by the local convective thunderstorms and squall lines. Squall lines are well-defined belts of intense thunderstorms moving at an average speed of about $25 \mathrm{~km} \mathrm{~h}^{-1}$ from east to west producing intense rain over relatively short time intervals (Ojo, 1977; Odekunle, 2004). Squall lines usually occur 200 to $600 \mathrm{~km}$ south of the ITD, where humid and hot air is deeper to allow the development of unstable conditions and associated heavy rainfall. A larger portion of the available atmospheric energy over the region occurs as latent heat of evaporation from soil or water. The high evapo-transpiration rate from the thick vegetation within the southern region of the WS, and the higher outgoing long wave radiation, are diffused by turbulence in the lower layers of the atmosphere resulting in important vertical fluxes of water vapor and sensible heat (Le Barbe et al., 2002; Idowu, 2007).

Mean annual rainfall totals over the WS range from over $3800 \mathrm{~mm}$ along the coastline to less than $200 \mathrm{~mm}$ over the far northern parts. For brevity and in the context of this study, records of daily rainfall have been regarded as records of individual storm. Widespread rainfall events with a total rainfall amount of more than $50 \mathrm{~mm} / 24 \mathrm{~h}$, and localized events with a total rainfall amount of more than $40 \mathrm{~mm} / 6 \mathrm{~h}$ are referred to as severe storms. It is equally important to note that most of the significant rainfall events are associated with thunderstorms and other deep convective systems, and they are altogether hereafter simply referred to as severe storms. In general, the prevailing characteristics of the humid WAM that flow from the ocean, characteristics of the squall lines, the ITD, and the topographical nature of the environment are the most important atmospheric forcing functions that characterize the development and severity of storms over the WS. Fig. 1 shows a typical severe storm path across the WS. The convective

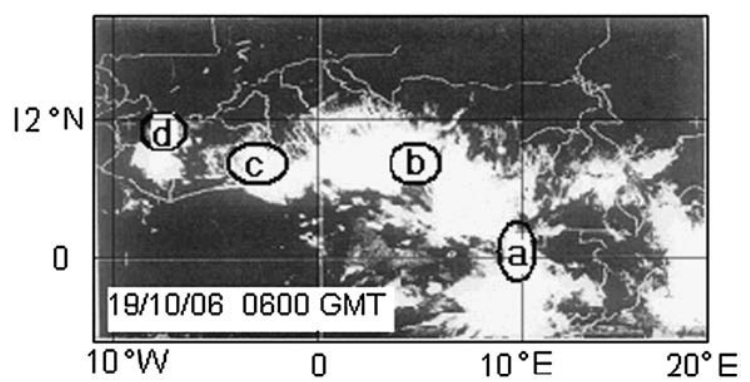

Fig. 1. Satellite imagery over the Western Sahel (WS) at 06:00GMT on 19 October 2006. Locations (a) to (d) indicate a typical storm path across the Western Sahel (Source: EUMETSAT).

weather which resulted into a severe storm event across the WS is clearly indicated. The storm moved across the region from location (a) to (d), and produced different rainfall intensities and duration at each of the locations as it traveled.

The recent increasing trend in the severity of floods across the WS, which is in most cases a result of severe storm events, necessitates better and improved severe storm prediction over the region. It is however very difficult and complex to accurately predict these storms partly because of the inaccuracies in NWP models earlier mentioned. A majority of the National Meteorological and Hydrological Services (NMHSs) in Africa are finding it difficult to run NWP models on their own, either due to a lack of computer resources, or a shortage of manpower. These meteorological centers currently interpret NWP model outputs from international global modeling centers subjectively when issuing daily weather forecasts and, not in all cases, these model products are representative of the local weather conditions. Statistical methods, for example Model Output Statistics (MOS), have recently become a very useful and necessary part of the overall process of weather forecasting at meteorological centers. MOS use large multiple regression equations to provide statistical relationships between the forecast output of NWP models (predictors) and the observed variables (predictands). As suggested by Kalnay (2003), Antolik (2003) and Wilks (2006), a combination of statistics gained through a long record of model output or NWP model forecast simulations compared to observation will help to quantify and express forecast uncertainties. This statistical method of improving model output is referred to as statistical post-processing. Statistical post-processing of NWP products could therefore improve NWP forecasts, and it is regarded as a very important contribution that assists practical weather forecasters in their duties (Michaelson, 1987; Coles, 2001; Casati et al., 2004; Jolliffe and Stephenson, 2003). Meanwhile, as the improvement, interpretation, and extension of NWP products becomes a priority at many national meteorological centers in Europe and other developed countries, very little has been done to make NWP results more usable in Africa.

Therefore, MOS is implemented in this study as a postprocessing method to improve precipitation forecasts generated by the United Kingdom Met Office Limited Area Model over Africa (Africa LAM) for the WS. The results are expected to meaningfully contribute to the issuance of more accurate and timely severe storm predictions over the WS. 


\section{The Africa LAM}

The Africa LAM, which is a configuration of the UK Met Office Unified Model (UM), is a $20 \mathrm{~km} \times 20 \mathrm{~km}$ resolution nonhydrostatic finite difference model with height as its vertical coordinate. The model uses the full primitive equations with virtually no approximations. The implementation of the Africa LAM is a special development initiative by the UK Met Office to support a major technical cooperation project for NWP in Africa. Since 2005, NWP products from Africa LAM became available to the NMHSs and other institutions through the UK Met Office's password-protected website (see http://www.metoffice.gov.uk/weather/africa/lam).

The Africa LAM has a fixed orthogonal horizontal grid, consisting of 432 rows and 432 columns on an un-rotated latitude-longitude grid which spans a latitude range of $37.5^{\circ} \mathrm{S}$ to $40.1^{\circ} \mathrm{N}$, and a longitude range of $20.0^{\circ} \mathrm{W}$ to $57.6^{\circ} \mathrm{E}$. The column and row spacing of the model are both $0.18^{\circ}$ (approximately $20 \mathrm{~km}$ at the equator). In the vertical the model uses the standard 38-level configuration, with the model levels following the terrain at the surface, but smoothed out as height increases. The lowest model level is at $10 \mathrm{~m}$ and the highest level is at $39 \mathrm{~km}$. In the operational simulation process, Lateral Boundary Conditions (LBCs) for the Africa LAM are provided on a three-hourly basis by the UK Met Office global model, and are applied in an eight-grid-point buffer zone around the edge of the nested area. Sea-surface temperatures are kept constant (as in their initial state) throughout the simulations, and lakes are assigned surface temperatures equal to that of their nearest seapoint. The model does not incorporate any diffusion. A timestep of $7.5 \mathrm{~min}$ is normally used during model simulations.

The Africa LAM has the same mathematical and physical configuration as the UM. As such, most of the improvement and parameterization schemes implemented in the UM are applicable to the Africa LAM (more information is available on: http:// www.metoffice.gov.uk/research/nwp/numerical). Worthy of mention, however, is that the Africa LAM employs a more detailed representation of the micro-physics of cloud formation. Water is contained in vapor, liquid, ice, and rain categories, with physically based parameterization of energy and moisture transfer. Convection with Convective Available Potential Energy (CAPE) closure, momentum transports, and convective anvils are also considered. All of these made the Africa LAM relatively effective in predicting severe storms over the WS. However, it is usually very difficult to predict West African Weather Systems (WAWS) which may be due to the zero Coriolis force in the tropics not allowing for well defined pressure systems; although the forecast of pressure systems might be regarded as primary variables. But as soon as one starts to consider secondary variables such as rainfall, the WAWS becomes extremely difficult to predict. It is therefore relevant to statistically improve the Africa LAM forecast outputs, using MOS, to better capture and account for some of the forecasting limitations of the model and thereby provide better and improved severe storm predictions for the WS.

\section{Data and methodology}

\subsection{Study area}

The area that extends from longitude $20.0^{\circ} \mathrm{W}$ to $30.0^{\circ} \mathrm{E}$ and latitude 0.0 (Equator) to $20.0^{\circ} \mathrm{N}$ is defined as the WS (Fig. 2). The WS is bordered in the north by the Sahara desert and in the south and west by the Atlantic Ocean. It covers the following countries; Benin Republic, Burkina Faso, Cape Verde, Cote d'Ivoire, Cameroon, Chad, The Gambia, Ghana, Guinea,

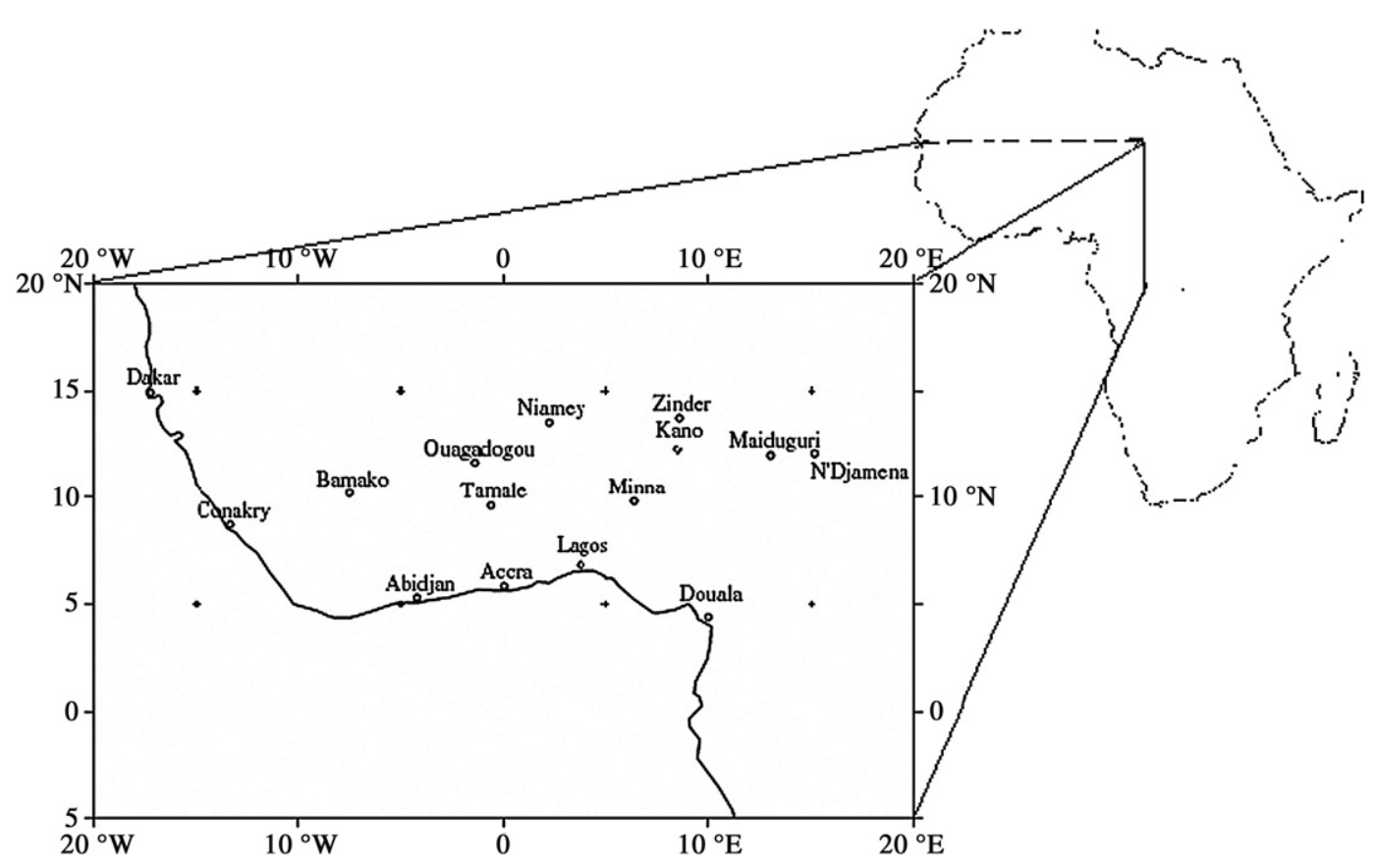

Fig. 2. Map of the Western Sahel (WS) which is the study area. Some of the meteorological stations considered in the study are indicated on the map (adapted from Omotosho, 2008). 
Guinea Bissau, Liberia, Mali, Mauritania, Niger, Nigeria, Senegal, Sierra Leone, Togo, and Sudan. It is estimated that more than 290 million people live in the WS which covers a total area of about 8 million $\mathrm{km}^{2}$ (ECOWAS-SWAC/OECD, 2006).

The WS has diverse climatological characteristics ranging from a wet equatorial climate in the southern region (from the southern coastline up to latitude $8.0^{\circ} \mathrm{N}$ ), to a wet and dry tropic climate in the central region (latitude $8.0^{\circ} \mathrm{N}$ to $12.0^{\circ} \mathrm{N}$ ), and a semi arid climate in the northern region (latitude $12.0^{\circ} \mathrm{N}$ to $20.0^{\circ} \mathrm{N}$ ). Generally, the WS is classified into two main climatic seasons, namely; (1) dry and (2) wet seasons. There is a clear contrast between the dry (January-February-March (JFM) and October-November-December (OND)) seasons and the wet (April-May-June (AMJ) and July-August-September (JAS)) seasons. The local impact of thunderstorms over the WS is usually sporadic, especially over the interior parts, mostly during the peak of the rain, usually during the JAS season (Odekunle, 2004; Idowu, 2007).

\subsection{Data collection}

For the period of January 2005 to December 2006, daily rainfall data were collected from 36 selected weather stations across the study area (see Fig. 2). 12 meteorological stations were selected across each of the three identified regions: Northern, Central and Southern regions of the WS. Meteorological data obtained from all of these selected stations are in conformity with the World Meteorological Organization (WMO) standards. Meaning that, the rainfall measuring equipment and techniques used in all of these stations are virtually the same. As mentioned before, an important feature of the MOS statistical post-processing technique is that historical observations are used, and compared with historical forecasts, in an effort to correct or minimize forecast errors and biases in NWPs. In this study, for the period mentioned above, daily rainfall amounts recorded for each of the stations were matched with the daily Africa LAM precipitation forecast outputs in order to check the capability of the model to significantly capture the rainfall amount during severe storm event(s). As suggested by Wilks (2006), the datasets are stratified into four seasons JFM, AMJ, JAS and OND in order for the MOS equations and their corresponding forecasts to incorporate different relationships between predictors and predictands at different times of the year. The station data are retrieved primarily from the National Climatic Data Center (NCDC) of the United States of America (see: http://www.ncdc.noaa.gov/oa/ncdc.html) with some observed rainfall datasets obtained directly from the local stations where available. Gridded $\mathrm{T}+24 \mathrm{~h}$ forecast dataset from the Africa LAM of total precipitation for the same period are also retrieved. Although different MOS equations are required for different forecast projections from the model, this study only focused on the $\mathrm{T}+24 \mathrm{~h}$ forecast projection. To compare observations with model results, the model value of the nearest grid point was chosen as the predictor, and the station data chosen as the predictand.

\subsection{Data processing and software}

Several methods were used in processing the datasets. The NCDC station data for rainfall originally coded in inches was
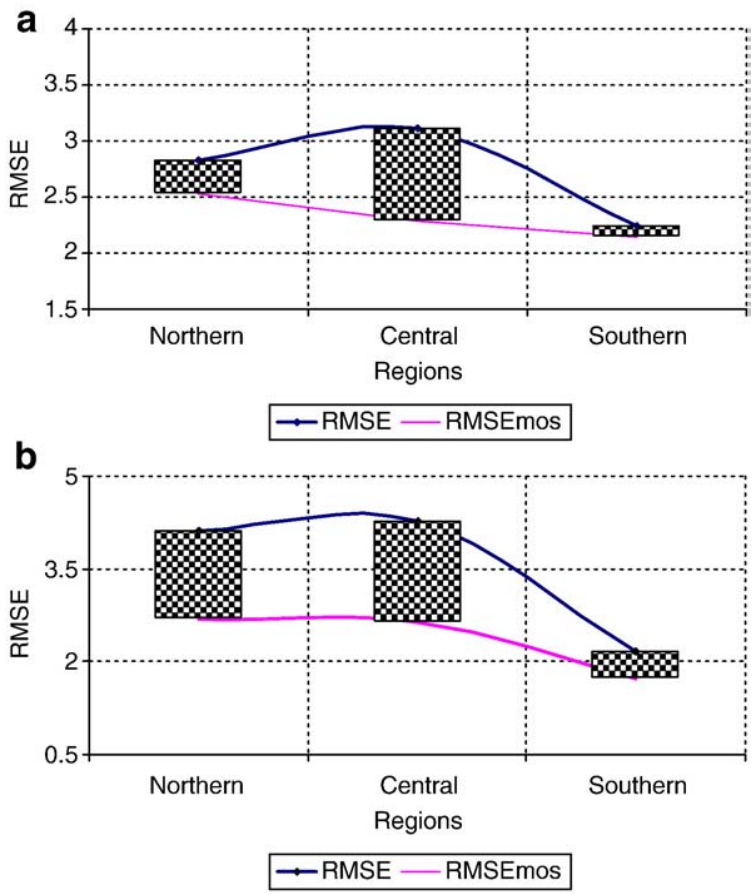

Fig. 3. Root mean squared errors (RMSEs) of the original Africa LAM T $+24 \mathrm{~h}$ rainfall forecasts compared to that of the MOS-corrected rainfall forecasts over the north, central and southern regions of the Western Sahel (WS) during (a) JFM and (b) OND seasons. RMSE is for the original Africa LAM rainfall forecasts and the RMSE $\mathrm{MOS}_{\text {is }}$ is for the MOS corrected rainfall forecasts. The dark grey blocks indicate the difference between RMSE and RMSE Mos values at each of the region of the WS.

converted into millimeters. The Africa LAM datasets originally coded in Grib format were converted to 'NetCDF' using the 'Xconv' software. ${ }^{1}$ The software, for example, makes it easy to convert Grib fields to NetCDF fields. The model's NetCDF files were then imported into Matrix Laboratory (MATLAB) to extract the model grid values that are closest to the observational station locations. In order to process and analyze the datasets to obtain the MOS results, the extracted model data (predictors) and station data (predictands) were imported into the Climate Predictability Tool (CPT) version 8.07 (released on the 31 August 2007), developed by the International Research Institute (IRI) of the United States of America.

\subsection{MOS regression analysis}

Although multivariate regression is normally used in MOS (Glahn and Lowry, 1972; Stanski et al., 1989; Wilks, 2006), simple linear regression was adopted in this study since our interest is to establish forecast relationship between the predictands and the predictors. The MOS regression analysis adopted here has exactly the same mathematical expression as the common simple linear regression equation. Hence, the regression

\footnotetext{
${ }^{1}$ The 'Xconv version 1.9.1.0' software is a data converter designed and released by Jeff Cole (j.cole@reading.ac.uk) of the University of Reading on the 3rd of March 2006
} 
Table 1

Africa LAM T +24 h rainfall forecasts compared to the MOS-corrected rainfall forecasts

\begin{tabular}{|c|c|c|c|c|c|c|c|c|c|c|c|c|}
\hline & \multicolumn{3}{|l|}{ JFM } & \multicolumn{3}{|l|}{ AMJ } & \multicolumn{3}{|l|}{ JAS } & \multicolumn{3}{|l|}{ OND } \\
\hline & RMSE & RMSE $_{\text {MOS }}$ & \%IM & RMSE & RMSE $_{\text {MOS }}$ & \%IM & RMSE & $\mathrm{RMSE}_{\mathrm{MOS}}$ & \%IM & RMSE & RMSE $_{\text {MOS }}$ & $\% \mathrm{IM}$ \\
\hline Northern & 2.83 & 2.53 & 11 & 4.21 & 3.17 & 25 & 4.12 & 2.66 & 35 & 4.12 & 2.68 & 35 \\
\hline Central & 3.12 & 2.29 & 27 & 5.89 & 2.79 & 53 & 4.89 & 1.53 & 69 & 4.26 & 2.63 & 38 \\
\hline Southern & 2.24 & 2.14 & 4 & 3.25 & 1.28 & 61 & 4.18 & 1.02 & 76 & 2.16 & 1.73 & 20 \\
\hline
\end{tabular}

The RMSE is for the original Africa LAM rainfall forecasts, RMSE ${ }_{\mathrm{MOS}}$ for the MOS-corrected rainfall forecasts and \%IM is the percentage forecast improvement achieved by introducing the MOS.

equation between $x$ (predictands or station observations) and $y$ (predictors or Africa LAM forecast output) is expressed as:

$y=a+b x+e$

where $a$ regression intercept

$b$ regression coefficient (or the slope)

e error or residual

The regression coefficient $b$ in Eq. (1) is therefore calculated the same way as the MOS regression coefficient $\left(\boldsymbol{f}_{\text {MOS }}\right)$. MOS regression analysis maximizes the inter-relationships between predictors and predictands, and thereby has the advantage of recognizing model predictability. The regression analysis is useful in that it provides the adjustment terms necessary to improve NWP forecast output biases and errors (Antolik, 2003; Kalnay, 2003).

\subsection{The MOS equation}

The MOS equations for this study take the form;

$O_{t}=X_{t}+F_{\mathrm{ADJ}}$

where

$\mathrm{O}_{t} \quad$ the MOS forecast

$X_{t} \quad$ Africa LAM forecast pertaining to the future time $t$, $F_{\mathrm{ADJ}} \quad$ the MOS correction term.

However, since $F_{\mathrm{ADJ}}$ is meant to account for the long term error differences between archived Africa LAM forecast outputs and the archived station observation datasets,

$F_{\mathrm{ADJ}}=O_{\text {stn }}-X_{\text {nwp }}$

where

$O_{\text {stn }} \quad$ archived station observations

$X_{\text {nwp }} \quad$ archived Africa LAM forecasts.

According to Neiley et al. (2002), the regression of $O_{\text {stn }}, X_{\mathrm{nwp}}$, $A_{e}$ against $\beta$ should be considered in order to obtain the MOS regression-based correction term $\left(F_{\mathrm{ADJ}}\right)$, therefore;

$F_{\mathrm{ADJ}}=A_{e}+f_{\mathrm{MOS}} * \beta$

where

$f_{\text {MOS }} \quad$ MOS regression coefficient

$\beta \quad$ average anomalies from the mean of original model forecasts,

$A_{e} \quad$ negative of the mean model bias.

With the CPT, the root mean squared error (RMSE) of the original model rainfall forecasts and that of the MOS corrected rainfall forecasts (RMSE $\mathrm{MOS}_{\text {) }}$ are calculated. The Percentage improvement (\%IM) by the MOS-corrected rainfall forecasts relative to the original Africa LAM rainfall forecasts are also calculated using Eq. (5).

$\% \mathrm{IM}=\left(\left(\mathrm{RMSE}-\mathrm{RMSE}_{\mathrm{mos}}\right) / \mathrm{RMSE}\right) \times 100$

(Davis, 2004)

\section{Results and discussion}

Results (Fig. 3, Table 1) show that when compared with the northern and southern regions of the WS during JFM and OND seasons, the Africa LAM MOS corrected rainfall forecasts recorded its largest improvement (\%IM) of about $38 \%$ over the central region. Fig. 3(a) and Table 1 further show that the MOS method could however not significantly improve $(\% \mathrm{IM}=4)$ the Africa LAM rainfall forecasts during JFM season, especially over the southern region of the WS. This could be partly because of the relatively smaller number of rain days usually recorded over the southern region of the WS during the JFM

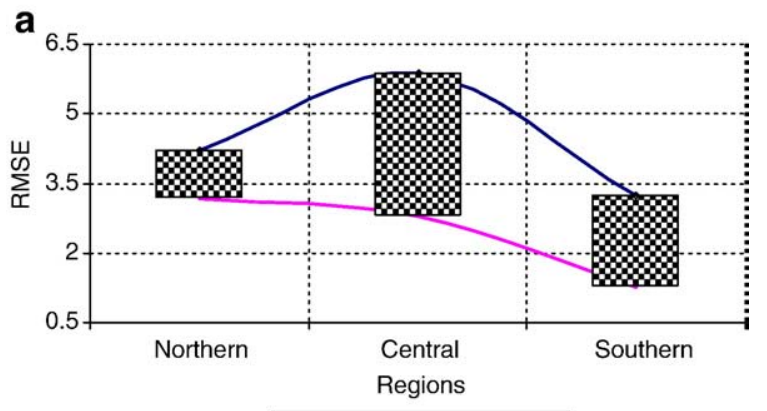

b

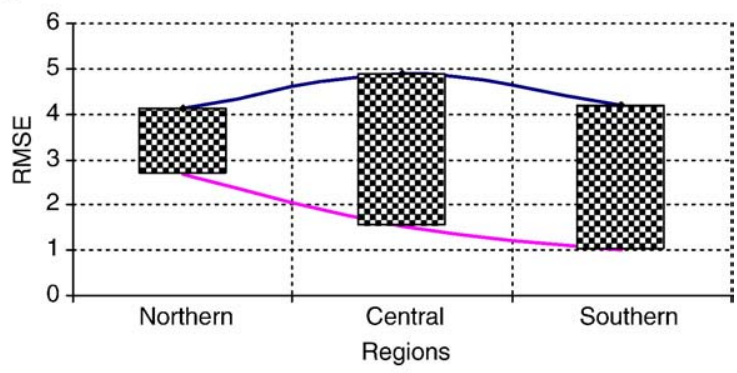

-RMSE —RMSEmos

Fig. 4. Same as in Fig. 3 but during (a) AMJ and (b) JAS seasons. 
Table 2

MOS correction terms used to formulate the MOS equations required for adjusting the Africa LAM T $+24 \mathrm{~h}$ rainfall

\begin{tabular}{|c|c|c|c|c|c|c|c|c|c|c|c|c|}
\hline & \multicolumn{3}{|l|}{ JFM } & \multicolumn{3}{|l|}{ AMJ } & \multicolumn{3}{|l|}{ JAS } & \multicolumn{3}{|l|}{ OND } \\
\hline & $A_{e}$ & $f_{\mathrm{MOS}}$ & $\beta$ & $A_{e}$ & $f_{\mathrm{MOS}}$ & $\beta$ & $A_{e}$ & $f_{\text {MOS }}$ & $\beta$ & $A_{e}$ & $f_{\mathrm{MOS}}$ & $\beta$ \\
\hline Northern & 1.53 & 0.85 & -0.48 & 2.24 & 1.67 & -0.40 & 1.79 & 1.20 & 0.33 & -1.62 & 0.79 & -0.25 \\
\hline Central & 1.85 & 1.57 & 1.27 & 3.62 & 1.43 & 0.71 & -2.84 & 2.50 & -0.96 & -3.35 & 1.84 & -0.34 \\
\hline Southern & -0.20 & 0.32 & -0.88 & -2.43 & 2.72 & 0.02 & -2.72 & 3.48 & -0.95 & -1.01 & 0.44 & -0.02 \\
\hline
\end{tabular}

$A_{e}$ is the negative of the mean model bias, $f_{\text {MOS }}$ is the MOS regression coefficient and $\beta$ is the average anomaly from the mean of model forecasts.

season. It could also suggest that the original Africa LAM rainfall forecasts over the southern region of the WS are relatively close to local observations, meaning that there is not much need for MOS forecast improvement in the southern region of the WS during the JFM season.

Results from Fig. 4 and Table 1 however reveal that the \% IM values recorded during AMJ and JAS seasons are significantly higher than those recorded during JFM and OND seasons (Fig. 3). The overall highest improvement of about $76 \%$ was recorded during JAS over the southern region. The AMJ and JAS are climatologically known as the raining period of the WS-the period when it is highly probable to experience high frequencies of severe storm events over the WS. Since the highest \%IM value from this study is obtained during the JAS season, it then makes sense to conclude that the study holds a greater prospect in improving severe storm predictions over the WS. In Table 2, the adjustment coefficients required to adjust the future Africa LAM rainfall forecasts over the WS are provided, and which by extension would help to improve the prediction of severe storm events over the region, at least within the $\mathrm{T}+24 \mathrm{~h}$ forecast period.

The MOS equations (Table 3 ) generated by this study, required to adjust the Africa LAM rainfall (precipitation) forecast errors and biases for the four seasons (JFM, AMJ, JAS and OND) over the three identified regions; Northern, Central and Southern regions of the WS are presented. Graphs of the RMSEs of the original Africa LAM rainfall forecasts and those of the MOS corrected forecasts are also presented in Figs. 3 and 4. From these graphs and Table 1, the benefits that the MOS statistical post-processing method hold in improving the original Africa LAM rainfall forecasts over the three identified regions of the WS and for each of the seasons are discussed.

Generally, the results (Figs. 3 and 4; Table 1) show improvements to original Africa LAM rainfall forecasts over the WS, especially as revealed by the \%IM values and the consistently lower RMSE $E_{\text {MOs }}$ values when compared with the original RMSE values.

Table 3

The MOS equations required to adjust Africa LAM T $+24 \mathrm{~h}$ rainfall forecasts over the north, central and southern regions of the Western Sahel (WS) for the JFM, AMJ, JAS and OND seasons

\begin{tabular}{llll}
\hline & Northern region & Central region & Southern region \\
\hline JFM & $O_{t}=X_{t}+1.12$ & $O_{t}=X_{t}+3.84$ & $O_{t}=X_{t}-0.48$ \\
AMJ & $O_{t}=X_{t}+1.57$ & $O_{t}=X_{t}+4.63$ & $O_{t}=X_{t}-2.38$ \\
JAS & $O_{t}=X_{t}+2.19$ & $O_{t}=X_{t}-5.24$ & $O_{t}=X_{t}-6.03$ \\
OND & $O_{t}=X_{t}-1.82$ & $O_{t}=X_{t}-3.98$ & $O_{t}=X_{t}-1.02$ \\
\hline
\end{tabular}

\section{Conclusions}

Major errors in the development of rainfall systems are often difficult to notice in NWP models. This might negatively affect forecasters' confidence in using NWP model forecast outputs. One approach that could be used to improve NWP outputs is to compare NWPs with what has been observed in history, and use that as an aid to try and, at least, reduce biases in NWPs. Such a process would involve statistical postprocessing technique. Therefore, MOS which is a statistical post-processing method has become very useful, and has even become a necessary part of weather forecasting at many meteorological centers (Glahn, 1985; Kalnay et al., 1990; Wilks, 2006). However, as the improvement, interpretation and extension of NWP products become a priority at many national meteorological centers in Europe and other developed countries, very little has been done to make NWP results more usable in Africa. This study therefore introduces the MOS statistical post-processing technique as a tool to improve NWP forecasts over the WS. In particular, the study showed that errors and biases in Africa LAM rainfall forecasts could be improved with MOS method. Such improvement will add value to ensuring better prediction of severe storm events over the WS. The MOS equations generated by this study required to improve the Africa LAM rainfall forecasts over the WS as presented in Table 3 and the graphs of the RMSEs between the original Africa LAM forecasts and the MOS corrected forecasts (Figs. 3 and 4) have been used to demonstrate the potential of the MOS technique to improve severe storm forecasts over the WS. From the results it became evident that the MOS method could improve Africa LAM precipitation forecast output up to about $75 \%$ over the WS. It is important to note that information given in this study is to guide scientists and weather forecasters in the WS region who are interested to further explore the application of MOS to improve weather forecasting in their own country. A comprehensive study to ensure adequate understanding of MOS is highly recommended before its application in operational forecasting. The authors intend to extend the knowledge gained from this research not only to carry out similar studies in the future over other parts of Africa, but also to implement the MOS method at the Nigerian Meteorological Agency.

\section{Acknowledgments}

The authors would like to thank the UK Met Office and the WMO for the graduate fellowship award given to the principal investigator. This study was conducted during the fellowship award tenure. 


\section{References}

Antolik, M.S., 2003. Model Output Statistics (MOS) - Objective Interpretation of NWP model output. Presented at the University of Maryland USA, $56 \mathrm{pp}$.

Casati, B., Ross, G., Stephenson, D.B., 2004. A new intensity-scale approach for the verification of spatial precipitation forecasts. Meteorol. Appl. 11, 141-154.

Coles, S., 2001. An Introduction to Statistical Modelling of Extreme Values. Springer. 208pp.

Davis, J.T. 2004. Bias removal and model consensus forecasts of maximum and minimum temperatures using the graphical forecast editor. NOAA NWS Office Tucson, Arizona, WR Technical Attachment Note No: 04-10.13pp.

ECOWAS-SWAC/OECD, 2006. Atlas on regional integration in West Africa. Annual Report for ECOWAS by the Sahel and West Africa Club (SWAC) of the Organization for Economic Co-operation and Development (OECD). 20pp.

Glahn, H.R., 1985. Statistical weather forecasting. In: Murphy, A.H., Katz, R.W. (Eds.), Probability, Statistics, and Decision Making in the Atmospheric Sciences. Westview, Boulder, CO. 335 pp.

Glahn, H.R., Lowry, D.A., 1972. The use of Model Output Statistics (MOS) in objective weather forecasting. J. Appl. Meteorol. 11, 1203-1211.

Idowu, O.S., 2007. Verification of numerical weather predictions for the Western Sahel by the United Kingdom Met Office Limited Area Model over Africa. Unpublished MSc dissertation, University of Pretoria, 100 pp.
Jolliffe, I.T., Stephenson, D.B., 2003. Forecast Verification. A Practitioner's Guide in Atmospheric Science. Wiley and Sons Ltd.. 220 pp.

Kalnay, E., 2003. Atmospheric modeling, data assimilation and predictability. Cambridge University Press, Cambridge. 281 pp.

Kalnay, E., Kanamitsu, M., Baker, W.E., 1990. Global numerical weather prediction at the National Meteorological Center. Bull. Am. Meteorol. Soc. 71, 1410-1428.

Le Barbe, L., Lebel, T., Tapsoba, D., 2002. Rainfall variability in West Africa during the years 1950-90. J. Clim. 15, 187-202.

Michaelson, J., 1987. Cross-validation in statistical climate forecast models. J. Clim. Appl. Meteorol. 26, 1589-1600.

Neiley, P.P., Meyers, N., Young, G., 2002. Ensemble dynamic MOS. Preprints, 16th Conference on Probability and Statistics in the Atmospheric Sciences, (Orlando, Florida). American Meteorological Society, pp. 102-106.

Odekunle, T.O., 2004. Rainfall and the length of growing season in Nigeria. Int. J. Climatol. 24, 467-479.

Ojo, O., 1977. The Climates of West Africa. Heinemann Educational Books Ltd. $218 \mathrm{pp}$.

Omotosho, J.B., 2008. Pre-rainy season moisture build-up and storm precipitation delivery in the West African Sahel. Int. J. Climatol. 28, 937-946.

Stanski, H.R., Wilson, L.J., Burrows, W.R., 1989. Survey of common verification methods in meteorology. WMO Research Report, 89-5, pp. 1-81.

Wilks, D., 2006. Statistical Methods in the Atmospheric Sciences. Academic Press. 255 pp. 